\title{
Laboratory Atmospheric Levels of Formaldehyde in Selected Laboratories used by Medical Students in a Tertiary Institution in Edo State, Nigeria
}

\author{
*EBOJELE, FO; IYAWE, VI
}

\author{
Department of Physiology, School of Basic Medical Sciences, College of Medical Sciences, University of Benin, Benin City, Nigeria \\ *Corresponding Author Email: frederick.ebojele@uniben.edu; Tel:08034419399
}

\begin{abstract}
This study was conducted to measure the laboratory atmospheric levels of formaldehyde in selected laboratories used by medical students in a tertiary institution in Edo state, Nigeria during the course of their medical training using a formaldehyde gas meter (EXTECH FM 200) ensuring that the laboratories served as the test groups while the lecture theatre served as the control. Data obtained from this study shows that medical students are exposed to various levels of formaldehyde in the different laboratories (Anatomy laboratory 1.71 $\pm 0.11 \mathrm{ppm}$; Histopathology laboratory $1.96 \pm 0.02 \mathrm{ppm}$; Medical Biochemistry laboratory $0.07 \pm 0.003 \mathrm{ppm}$ and Physiology laboratory $0.05 \pm 0.002 \mathrm{ppm}$ ) and these values are above the recommended limit prescribed by standard organizations. Hence, it was therefore concluded that measures should be taken to ensure reduction of formaldehyde air levels in the Anatomy and Histopathology laboratories in order to protect the medical students from the harmful effect of formaldehyde.
\end{abstract}

\section{DOI:https://dx.doi.org/10.4314/jasem.v25i10.1}

Copyright: Copyright $(\odot 2021$ Ebojele and Iyawe. This is an open access article distributed under the Creative Commons Attribution License (CCL), which permits unrestricted use, distribution, and reproduction in any medium, provided the original work is properly cited.

Dates: Received: 22 August 2021; Revised: 17 September 2021; Accepted: 06 October 2021

Keywords: formaldehyde, laboratories, limit, atmospheric level, medical students

Formaldehyde is colourless, flammable and have a pungent smell. It is soluble in water and its aqueous solution is generally called formalin which contains about $37 \%$ of formaldehyde and about $10-15 \%$ methanol which has an inhibiting effect and helps to prevent polymerization (Gerberich and Seaman, 2004). It is used to fix tissues which are relevant for microscopic as well as histological studies. It is also important in embalming human and animal remains thereby preventing them from undergoing decomposition thus, the use of formaldehyde finds relevance in the histopathology laboratories, mortuaries and Anatomy laboratories (IARC, 2006). Apart from the above mentioned laboratories formaldehyde is also utilized in other industrial applications like the manufacture of phenolformaldehyde, melamine-formaldehyde, ureaformaldehyde and polyacetal resins (IARC, 2006). These resins can be used as adhesives when manufacturing particle board, plywood, furniture, fiber board and other products derived from wood (Gerberich and Seaman 2004). It has been reported that exposure to formaldehyde occurs mainly through inhalation but it may also occur through the gastrointestinal tract if ingested accidentally and to a lesser extent it could occur through the skin (IARC, 2006). The concentration or level of formaldehyde vapour in the air is measured in parts per million (ppm) and several organizations in the world have established standards which defined the limit to which an individual can be exposed to formaldehyde. The American Conference of Governmental Industrial Hygienist (USA-ACGIH, 2002) suggested a ceiling limit of $0.3 \mathrm{ppm}$ as recommended standard while the National Institute for Occupational Safety and Health (USA-NIOSH, 1986) suggested a ceiling limit of $0.1 \mathrm{ppm}$. The Japanese Society for Occupational Health in 2003 suggested a ceiling limit of $0.5 \mathrm{ppm}$ while the Japan Ministry of Health, Labour and Welfare (MHLW) in 2002 set limit values for environmental exposure to formaldehyde at $0.08 \mathrm{ppm}$ as an average for general workplaces and $0.25 \mathrm{ppm}$ for specific workplaces like formaldehyde factories and gross anatomy laboratories. Attention has been drawn to formaldehyde regarding its possible health hazards and it is claimed to be carcinogenic, neurotoxic, embryotoxic, teratogenic, cytotoxic, genotoxic and allergenic (US Environmental Protection Agency, 1999; IARC, 2006). Some published reports have suggested that exposure to formaldehyde could be associated with adverse effects on the respiratory health (Mathur and Rastogi, 2007). In the tertiary institution in this study, medical students in addition to other laboratories pass through the Anatomy, Medical Biochemistry, Physiology and Histopathology laboratories in the course of their training where chemicals especially formaldehyde are freely used. Therefore, the objective of this study is to measure the 
laboratory atmospheric levels of formaldehyde in these selected laboratories used by medical students in the tertiary institution in Edo state, Nigeria to ascertain if the exposure level is within the acceptable limits prescribed by regulatory organizations.

\section{MATERIALS AND METHODS}

Study Location: Four laboratories in the University of Benin which medical students are required to pass through during the course of their training were selected for this study and these include: Anatomy laboratory, Medical Biochemistry laboratory, Physiology laboratory and Histopathology laboratory while the lecture theatre where students received lectures was used as the control site. Ethical approval was obtained from the College Research Ethics Committee, University of Benin before commencement of this work.

Measurements of formaldehyde air level: Formaldehyde air level was measured using Formaldehyde Gas Meter (EXTECH FM200). The meter is automated, calibrated and has an external probe that traps air and detects the air levels of formaldehyde which are ultimately displayed on the meter screen. Apart from formaldehyde air levels the meter also measures the room temperature as well as the relative humidity of the air in the site being measured. Five measurements were taken on five different occasions in the four laboratories as well as the control site and the average was calculated and taken as the air exposure level. Within the laboratories measurements were taken at the four corners of the room as well as at the centre making up the five measurements and the average was calculated. This measurement was repeated on four other separate occasions in the laboratories and control site.

Statistical Analysis: Statistical analysis was done using Graph pad prism version 5.0. Results was presented as Mean \pm SEM. Analysis of Variance was used to compare the means of test and control values while post hoc test was done using Student Newman Keul's test and a p-value of less than 0.05 was considered as statistically significant.

\section{RESULTS AND DISCUSSION}

Formaldehyde air levels in the different laboratories are shown in Figure 1. It was observed that there was a significant increase in formaldehyde air level in the Anatomy laboratory when compared with the control $(p<0.05)$. This significant increase was also observed in the Histopathology laboratory. However, there was no significant difference in the Medical Biochemistry laboratory and Physiology laboratory when compared with the control. Figure 2 shows the Room Temperature of the four laboratories and the control site. It was observed that there was significant increase in the room temperature of the Medical Biochemistry laboratory and Physiology laboratory when compared with the control $(\mathrm{p}<0.05)$ while there was no significant difference in the room temperature of the Anatomy and Histopathology laboratories when compared with the control. Figure 3 shows the Relative Humidity of the four laboratories and control site. It was observed that there was a significant decrease in the relative humidity of the Medical Biochemistry and Physiology laboratories when compared with the control $(\mathrm{p}<0.05)$ while there was no significant difference in the Anatomy and Histopathology laboratories when compared with the control.

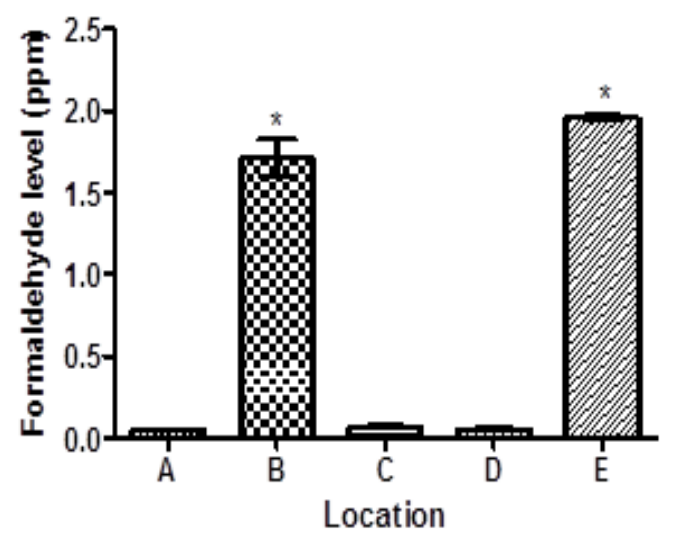

Fig 1: Mean formaldehyde ail level of control site and selected laboratories

$\mathrm{A}=$ control site $\mathrm{B}=$ anatomy laboratory $\mathrm{C}=$ medical biochemistry laboratory; $\mathrm{D}=$ physiology laboratory, $\mathrm{E}=$ histopathology laboratory

*significant values are mean \pm SEM compared to control $(* \mathrm{p}<$ $0.05)$

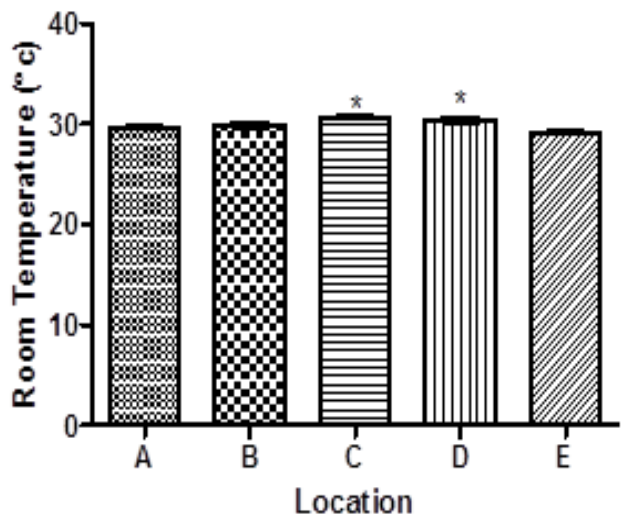

Fig 2: Mean room temperature of control site and selected laboratories

$\mathrm{A}=$ control site; $\mathrm{B}=$ anatomy laboratory; $\mathrm{C}=$ medical biochemistry laboratory; $\mathrm{D}=$ physiology laboratory, $\mathrm{E}=$ histopathology laboratory

*significant values are mean \pm SEM compared to control $(* \mathrm{p}<$ $0.05)$ 


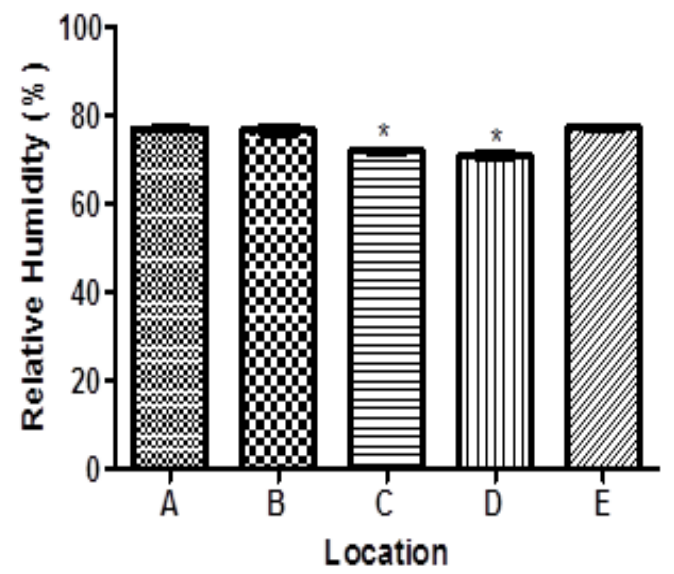

Fig 3: Mean relative humidity of control site and selected laboratories

$\mathrm{A}=$ control site $\mathrm{B}=$ anatomy laboratory; $\mathrm{C}=$ medical biochemistry laboratory; $\mathrm{D}=$ physiology laboratory, $\mathrm{E}=$ histopathology laboratory

*significant values are mean \pm SEM compared to control $(* \mathrm{p}<$ $0.05)$

Concerns for the possible health effect of exposure to formaldehyde has led some international organizations to set limit of exposure beyond which level it may be considered as unsafe for the individual's health. The Japanese Society for Occupational Health suggested a ceiling limit of $0.5 \mathrm{ppm}$ while the Japan Ministry of Health, Labour and Welfare (MHLW) set limit values for environmental exposure to formaldehyde at $0.08 \mathrm{ppm}$ as an average for general workplaces and $0.25 \mathrm{ppm}$ for specific workplaces like formaldehyde factories and gross anatomy laboratories. The American Conference of Governmental Industrial Hygienist (USA-ACGIH) suggested a ceiling limit of $0.3 \mathrm{ppm}$ while the National Institute for Occupational Safety and Health (USA-NIOSH) suggested a ceiling limit of $0.1 \mathrm{ppm}$. During the course of training Medical students of the University of Benin are required to go through the Anatomy, Medical Biochemistry, Physiology and Histopathology laboratories respectively and this exposes them to formaldehyde. From this study it was observed that the air exposure level of formaldehyde in the Anatomy laboratory was $1.71 \pm 0.11$ while that for Histopathology laboratory was $1.96 \pm 0.02$ and when these values are compared with the recommended limit it is above every values prescribed by the different organizations. These suggest that the health of the medical students who pass through these laboratories may be at risk. The exposure level in the Medical Biochemistry laboratory was $0.07 \pm 0.003$ which reveals that the laboratory may not pose any formaldehyde related health effect to the medical students as the values recorded are below every prescribed limit. This situation also holds true for the Physiology laboratory which had an exposure level of $0.05 \pm 0.002$ which is below the ceiling. The high level of exposure to formaldehyde in the Anatomy laboratory recorded in this study is also in agreement with the study carried out by Hafiz (2011) who equally reported higher levels of formaldehyde in the Anatomy laboratory when compared with other laboratories of Sharjah University in the United Arab Emirate. In the study of Akbar-Khanzadah et al. (1994) formaldehyde exposure in the Anatomy laboratory were reported to exceed the prescribed limit which also agrees with the observation of this study. Similar observations were also reported in the studies carried out by Tanaka et al. (2003) and Ohmichi et al. (2006).

Conclusion: Following the observations from this study we therefore conclude that measures should be taken to ensure reduction of atmospheric levels of formaldehyde in the various laboratories which may include introduction of proper ventilation system, air extractors, formalin adsorbers, as well as use of personal protective equipment like facemask and these may ultimately help to protect the medical students from the harmful effect of formaldehyde.

\section{REFERENCES}

Akbar-Khanzadah, F; Vaquerano, MU; AkbarKhanzadah, M; Bisesi, MS (1994). Formaldehyde exposure, acute pulmonary response, and exposure control options in a gross anatomy laboratory. Am. J. Ind. Med. 26: 61-75.

American Conference of Governmental Industrial Hygienists (ACGIH) TLVs and BEIs (2002). Threshold Limit Values for Chemical Substances and Physical Agents, Biological Exposure Indices. Cincinnati, $\mathrm{OH}$.

Gerberich, HR; Seaman, GC (2004). Formaldehyde. Kirk-Othmer encyclopedia of chemical technology. New York, NY: John Wiley \& Sons. Pp107-128.

Hafiz, OA (2011). Preliminary study: Formaldehyde exposure in laboratories of Sharjah University in UAE. Indian J. Occup. Environ. Med. 15(1):3337.

IARC (2006). IARC monographs on the evaluation of carcinogenic risks to humans. Vol. 88. Formaldehyde, 2-butoxyethanol and 1-tertbutoxypropan-2-ol. Geneva, Switzerland: Inter. Agency. Res. Cancer. 39-93, 273.

Japan Society for Occupational Health. (2003). Recommendation for Occupational Exposure 
Limit (2003 ver.), Formaldehyde. JUOEH. 46: 147-157.

Mathur, N; Rastogi, SK (2007). Respiratory effects due to occupational exposure to formaldehyde; systematic review with meta-analysis. Indian $J$. Occup. Environ. Med. 11: 26-31.

Ministry of Health, Labour and Welfare (2002). Guidelines for reducing formaldehyde concentrations in Indoor air of workplaces, 15 March 2002. Tokyo: MHLW.

National Institute for Occupational Safety and Health (1986): Registry of Toxic Effects of Chemical Substances, 1985- 1986.
Ohmichi, K; Komiyama, M; Matsuno, Y; Takanashi, Y; Miyamoto, H; Kadota, $\mathrm{T}$ (2006). Formaldehyde exposure in a gross anatomy laboratory-Personal exposure level is higher than indoor concentration. Environ. Sci. Pollut. Res. Int. 13:120-124.

Tanaka, K; Nishiyama, K; Yaginuma, H; Sasaki, A; Maeda, T; Kaneko, SY (2003). Formaldehyde exposure levels and exposure control measures during an anatomy dissecting course. Kaibogaku Zasshi. 78:43-51.

US. Environmental Protection Agency (1999). Integrated Risk Information System (IRIS) on Formaldehyde. National Center for Environmental Assessment, Office of Research and Development, Washington DC. 